\title{
A bibliometric study on SCRUM approach: patterns, trends and gaps
}

Antônio Carlos Bonassa' - Univ. de São Paulo - Escola Politécnica - Dep. de Engenharia de Transporte Marly Monteiro de Carvalho² - Univ. de São Paulo - Escola Politécnica - Dep. de Engenharia de Produção

ABSTRACT After Agile Manifesto success in the software development arena, the literature on Agile methods, particularly SCRUM has increased. This study aims to present a systematic literature review of SCRUM literature, identifying the main evolution patterns, trends, and gaps. The research methods combine the bibliometric approach with content analysis. The results show that despite the increase interesting on agile methods, SCRUM utilization is decreasing and/or being replaced by another project management method and it face so strong barriers to expanding in other sectors than software. The main advantages of applying SCRUM pointed out in the review are increase customer satisfaction at the same time that reduced associated costs and development time.

Keywords Agile. SCRUM. Project Management. Bibliometric Study. 


\section{INTRODUCTION}

Since the Agile Manifesto in 2001, several agile software development methods have come into practice, such as eXtreme Programming, Feature Driven Development and SCRUM (VLAANDEREN et al., 2011).

After Takeuchi and Nonaka (1986) first publications, SCRUM has attracted the interest of software project management community have been used in widespread situations (DINGSØYR et al., 2012, STETTINA; HÖRZ, 2014). Agile principles are implemented at both project and organization levels so as to create the adaptive products that are easier and less expensive to change and adaptive project teams that can respond rapidly to the changes in their project's ecosystem (PIKKARAINEN et al., 2008).

Rising and Janoff (2000) describe SCRUM as a development process for small teams, which includes a series of short development phases or iterations. A SCRUM team is given significant authority and responsibility for many aspects of their work, such as planning, scheduling, assigning tasks to members, and making decisions (MOE et al., 2010). The team focus is on delivering executable code and sees people as the strongest ingredient of software development (MAURER; MARTEL, 2002).

While agile project management is a trend in the Information Technology (IT) industry, there are also many organizations which now realize that traditional heavy-weight processes are slow, and lack interaction between customers and the product development teams (SCHWABER, 2002; SALO; ABRAHAMSSON, 2008; DYBÅ; DINGSØYR, 2008). Traditional process management - by continuous measurement, error identification, and process refinements - strove to drive variations out of processes, it assumes that variations are the result of errors (HIGHSMITH; COCKBURN, 2001). Thus, traditional enterprises have also become attracted by the promise of a faster time to market for their projects (WAARDENBURG; VLIET, 2013, BENEFIELD, 2008). In the professional arena, there are new certifications related to agile method as PMI Agile Certified Practitioner (PMI-ACP) of Project Management Institute (PMI, 2015)

Conboy (2009) pointed out a number of significant conceptual shortcomings with agile methods associated literature, as "a lack of clarity, theoretical glue, parsimony, limited applicability, and naivety". For Dybå and Dingsøyr (2008), SCRUM is popular in the industry; however, there is a lack of research to be addressed agile project management methods, particularly SCRUM.

The few studies on SCRUM (DINGSØYR et al., 2012), the increasing interesting on agile project management methods (STETTINA; HÖRZ 2014) and clear demand for more research on its utilization (HUMMEL 2014), suggested there is space for new research on this subject and a systematic literature review can point out the evolution patterns, trends, and gaps in SCRUM literature. The research methods combine the bibliometric approach with the content analysis.

The article is structured into six sections. Section 1 presents the research topic, its context, and its objectives. Section 2 presents the research method and Section 3 results found. Section 4 is dedicated to discussing the findings while section 5 is devoted to conclusions and limitations. 


\section{SCRUM OVERVIEW}

Takeuchi and Nonaka (1986), using the SCRUM rugby metaphor, having the project as the ball passed within the team as it moves as a unit up, enables real-time bottleneck management while pushing the group forward. The authors presented six characteristics presented on this holistic approach: built-in instability, self-organizing project teams, overlapping development phases, multi-learning, subtle control, and organizational transfer of learning.

For Dybå and Dingsøyr (2008) SCRUM is a management-oriented approach that mainly covers aspects related to project management. SCRUM differs from traditional approaches in that it assumes that analysis, design, and development processes are largely unpredictable (FITZGERALD et al., 2006). SCRUM fits project management situations where it is difficult to plan ahead; thus, the work is coordinated in a daily stand-up meeting in increments (sprints), where feedback loops constitute the core element (SCHWABER; BEEDLE 2001).

SCRUM is developed by a self-organizing team, lead by the SCRUM master, who is in charge of solving problems (SCHWABER; BEEDLE 2001). SCRUM method defines three main roles: the Product Owner, SCRUM Master, and SCRUM team members. The Product Owner acts as the single 'voice of the customer' collecting and prioritizing customer needs onto a prioritized list of items: the product to do list, known as backlog. The SCRUM Master facilitates the SCRUM team in achieving its goal (VLIETLAND; VLIET, 2015). Team members perform the tasks according to the sequence defined by them in daily meetings.

During the initial planning phase, the project team must develop its architecture and identify the chief architect. The chief architect defines the development project's vision based on the architecture defined and ensures that vision's consistency throughout all the development phases.

During the planning phase, the group determines the scope of the next software release and its requirements, based on a combination of business priorities and technical estimates. And it is accepted that this plan will probably change (FITZGERALD et al., 2006). Tasks are them grouped into sprints.

Rising and Janoff (2000) describes that a sprint produces a visible, usable, deliverable product that implements one or more user interactions with the system. The key idea behind each sprint is to deliver valuable functionality. The team tracks all currently identified tasks, capturing them in a list called the backlog. The backlog drives team activity. Before each new sprint, the team updates the backlog and reprioritizes the tasks selecting the top ones to work on. Hoda et al. (2013) call attention to the fact that SCRUM is characterized by sprints work cycles, typically two to four weeks. Once a requirement has been fully specified, with the approval of a developer, the requirement can be dropped from the backlog list (VLAANDEREN et al., 2011).

Important to notice that organization can make one very important decision at the end of each sprint: whether or not to continue with each product development project. 


\section{RESEARCH METHOD}

This study aims to investigate the literature pattern on SCRUM by understanding the key authors and publications that impact the academic community and the dissemination of SCRUM. Moreover, it aims to identify the main trends and gaps. To achieve this objective the methodological approach is a systematic literature review, combining the bibliometric approach with the content analysis.

Pritchard (1969) define bibliometric approach as to shed light on the processes of written communication and of the nature and course of development of a discipline by means of counting and analyzing the various facets of written communication. Systematic literature review differs from traditional narrative reviews by adopting a replicable, scientific and transparent process that aims to minimize bias through exhaustive literature searches of published and unpublished studies and by providing an audit trail of the reviewer's decisions, procedures, and conclusions (COOK; MULROW; HAYNES, 1997).

At the same time that bibliometric application can stimulate useful discussion among scientists and research managers about publication strategies and research directions (MOED 2002) and generate qualitative analysis through content analysis, helping to understand the key concept and research trends.

\subsection{Data collection}

Data collection started by searching for topics definition, i.e. by defining what would be the words or expression entered in the search engine from academic databases as search leads for finding studies related to this study objective. We first started by entering the single word "SCRUM" as Topic to be searched on the ISI Web of Science (WoS) database. The search was further limited to only peer-reviewed articles containing the previously mentioned word, which was made by selecting only "ARTICLES OR REVIEWS" as acceptable "Document Type". Such query retrieved 1,234 documents as the search result. These documents were analyzed according to the fit with the research theme and objective. It was verified that the word SCRUM is used in other fields with a different meaning as in endocrinology metabolism area, in which there were published 86 articles.

Thus, based on Dybå and Dingsøyr (2008) and Rising and Janoff (2000) analysis, the strings "AGILE" and "SCRUM" were introduced as searching topics. Those words together ("AGILE" AND "SCRUM") were enough to create a broad search for all SCRUM application. Queries limited "ARTICLES OR REVIEWS" on the "Document Type" field and the time limit of December 2015 was set for publication period.

Two databases for research publications (WoS and SCOPUS) were selected as a data source for the bibliometric study proposed. Using the same search structure presented, while WoS database contributed with 91 articles, SCOPUS presented 156 articles. The consolidation of entries generated by the queries revealed that 62 articles were in both databases, resulting in 185 articles in the initial sample. From this initial sample, just 10 articles ( 5\%) were eliminated due to a misalignment of purposes with the theme of this study, resulting in 175 articles for the first analysis (see Figure 1). 
For network analysis purpose, just 88 articles have available all the metadata and thus the Network Phase is based on these sub-sample of 88 articles. For the content analysis, the top cited articles were selected to be in depth analyzed. Reading the references of the top articles, we found 6 other studies that stood out, thus they were added to the existing sample for content analysis. The content analysis help to perform the in-depth qualitative analysis, identifying trends, research gaps, the core research constructs, and critical latent and manifest variable for building research framework (DURIAU et al., 2007, CARVALHO et al. 2015). In order to have enough understand and properly analyze the bibliometric study output we fully read 18 articles (about $22 \%$ of the sample), whose were responsible for about $60 \%$ of all citations received by the complete set ( 79 articles) and $100 \%$ of the other 61 articles abstracts. All steps taken in this study are presented in Figure 1.

Figure 1 - Literature review workflow.

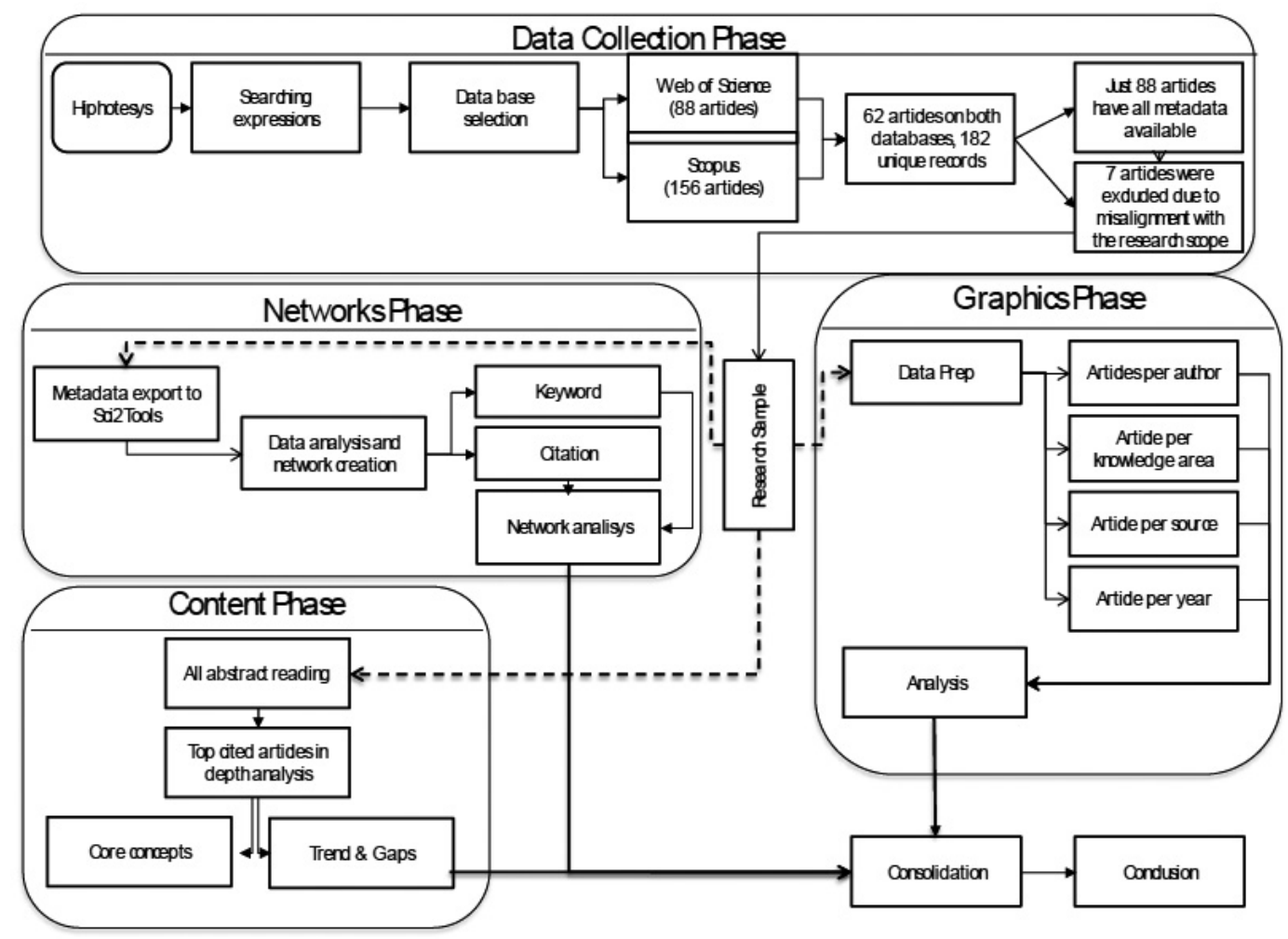

Source: Author (2015). 


\subsection{Data analysis}

The bibliometric analysis present in this study starts by counting publications per journal per year. Publication counting makes it possible to identify journals that often addressed the theme and to examine the way the publications evolved over time (CARVALHO et al., 2013). A citation count per journal per year was also performed, citations measure impact and influence, tracking citations and understanding their trends in context is a key to evaluating the impact and influence of researchers (Using Bibliometric: A Guide to Evaluating Research Performance with Citation Data available at .http://ip-science.thomsonreuters.com/ news/2008-07/8465001/ accessed on Jan 12th, 2015).

Following, four relational networks were constructed: co-citation, article citation, co-authorship, and keyword. According to Qiu et al. (2014), author-level is importantly dominated at aggregation levels, because, for journals, institutions and countries, every type of network is formed through authors' academic relations such as collaboration or citation among authors. Paper citation network represents groups working with each other having thematic affinity (CARVALHO et al., 2013). Co-authorship networks document scientific collaboration through published articles, where nodes are authors and a link represents the fact that two authors have written at least one article together. Co-authorship networks are thus undirected networks (DING, 2011), representing authors working together.

The analysis follows by studying publication by research area. Such analysis may reveal how to spread the research main topic "SCRUM" is among different research area, what may be a proxy for how spread it is among different utilization fields. In other words, it may shed light on the fact that "SCRUM" could be used not only by software related project management but also by non-IT related ventures.

During network creation and analyzes we used the centrality indicator measurement, where the centrality of a node $\mathrm{X}$ is defined as the sum of the centralities of the nodes with edges pointing to $\mathrm{X}$, divided by a constant. The displayed size of a node represents its centrality (ZIEGLER, 2009). Freeman (1978) formalized three different measures of node centrality: degree, closeness, and betweenness, measures generalized to weighted networks. Opsahl et al. (2010) explain the measurements defining degree as the number of nodes that a focal node is connected to, measuring the involvement of the node in the network, closeness as being in a position to reach others quickly and betweenness assess the degree to which a node lies on the shortest path between two other nodes, able to funnel the flow in the network. 


\section{RESULTS}

This section presented presents the main results of the graphics phase and network phase.

\subsection{Graphic phase}

As mentioned before, the agile manifest started on software area, and so, the main journals concerning the number of publications in the studied sample are from Information Technology (IT) area. Two journals stood out with more than 10 articles published: Information and Software Technology (14 articles) and Journal of Systems and Software (12 articles) (see Table 1). It is important to note that these two journals are presented in both databases WoS and Scopus; however, the fifth journal Dr Dobb S Journal (8 articles), for instance, is just in the Scopus database and there in no impact factor calculate in the Journal Citation Report (JCR).

In the period of analysis, there is an increasing trend in recent years, starting in 2010. The most prolific year of the series is 2015 with 32 studies were published. Table 1 shows that the number of publications in the last decade was three times less than this decade.

Table 1 - Number of publications per journal and per year.

\begin{tabular}{|c|c|c|c|c|c|c|c|c|c|c|c|c|c|c|c|c|c|}
\hline Source & ઠे & চ్ర & ণั & ஜั̀ & ષ্ণ & 농 & ઠे & ઠें & ஜั & ஓे & 을 & $\overline{\bar{i}}$ & ำ & $\bar{m}_{i}^{m}$ & $\frac{i}{i}$ & $\stackrel{n}{\frac{n}{2}}$ & 퓸 \\
\hline $\begin{array}{l}\text { Information and } \\
\text { Software Technology }\end{array}$ & & & & & & & & & 1 & & 1 & 1 & 1 & 2 & 4 & 5 & 14 \\
\hline $\begin{array}{l}\text { Journal of Systems } \\
\text { and Software }\end{array}$ & & & & & & & & & & & 2 & & 7 & 2 & 1 & & 12 \\
\hline $\begin{array}{l}\text { Lecture Notes In } \\
\text { Computer Science }\end{array}$ & & & & 2 & 2 & & & & & & & & & & 4 & & 8 \\
\hline $\begin{array}{c}\text { IEEE } \\
\text { Software }\end{array}$ & & & & & & 1 & & & & 2 & 1 & 1 & 2 & & 1 & & 8 \\
\hline $\begin{array}{l}\text { Dr Dobb S } \\
\text { Journal }\end{array}$ & & & & & & & 1 & 2 & 3 & & & & & & & & 6 \\
\hline $\begin{array}{c}\text { Empirical Software } \\
\text { Engineering }\end{array}$ & & & & & & & & & 1 & & 1 & & & & 1 & 2 & 5 \\
\hline $\begin{array}{l}\text { Other journals with } 4 \\
\text { publications or less }\end{array}$ & 1 & 1 & 1 & 0 & 2 & 3 & 7 & 2 & 6 & 3 & 5 & 13 & 12 & 20 & 20 & 25 & 122 \\
\hline Total & 1 & 1 & 1 & 2 & 4 & 4 & 8 & 4 & 11 & 5 & 10 & 15 & 22 & 24 & 31 & 32 & 175 \\
\hline
\end{tabular}

Journals are listed in descending order of articles published.

Source: Author (2015). 
The predominance of the publication in SCRUM is from United States (USA) with 15\%. Brazil is responsible for $7 \%$ of the publications (6 articles). According to the research area classification provided by the WoS, most of these publications are classify in computer science field (82\%), followed by engineering (24\%), reinforcing the fact that the vast majority of studies are related to software development.

\subsection{Network Phase and citation analysis}

As mentioned in the research methods section, the network phase was performed based the sub-sample of 91 articles with all metadata available. In this group total citation count is 933 citations, which evolution pattern is presented in Figure 2, shifting up in recent years. As the citations vary according to the databases, for the descriptive analysis of citation, the WoS database was used. Two parameters are important to analyze the citations: total citations and average citation per year. The total citation has the bias of pointing out the oldest publications and average citation is less sensible to the publication year. Based on these parameters, Figure 3 and Table 2 show citation evolution pattern of the top cited article in the sample.

Figure 2 - Citations evolution over time.

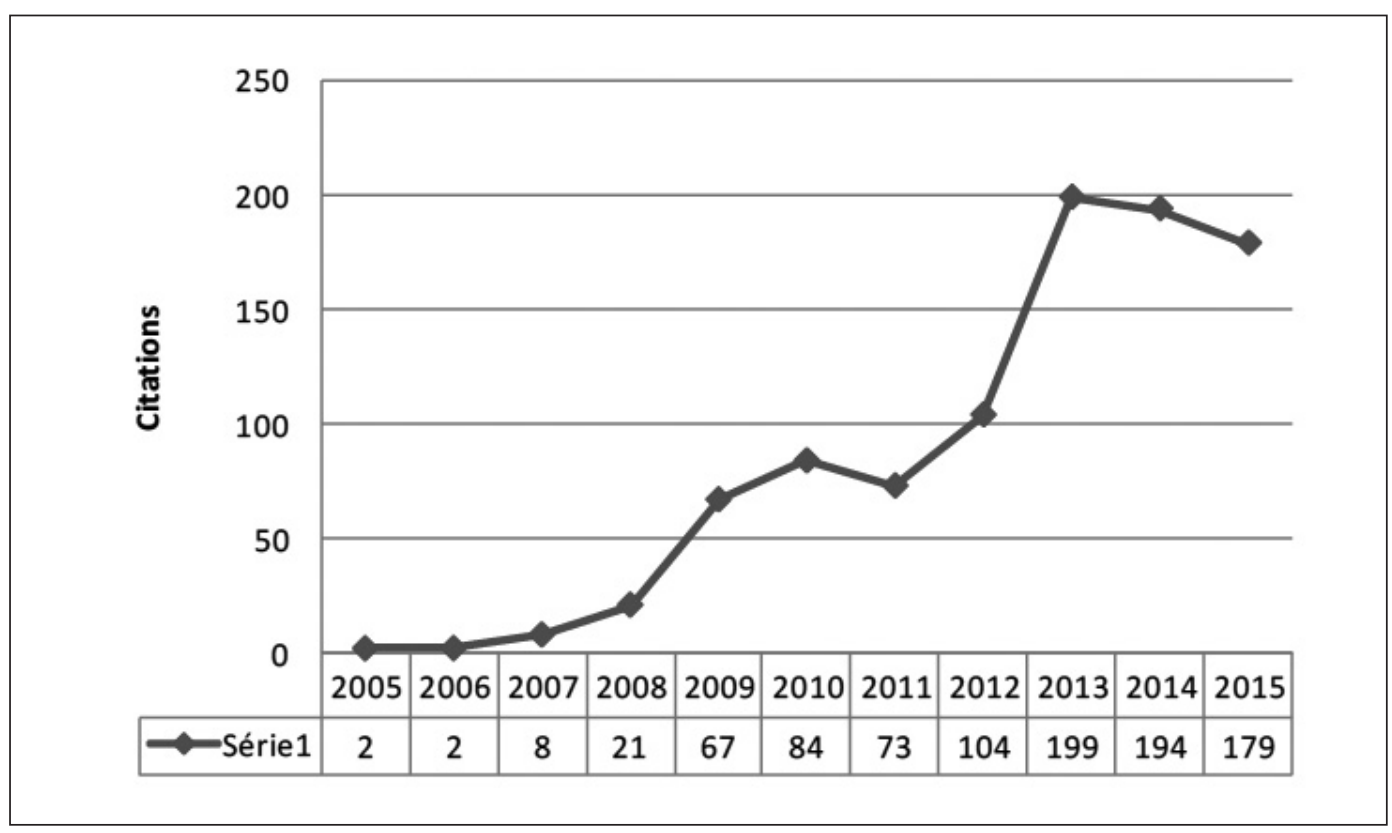

Source: Author (2015). 
All the top articles in the citation rank (see Table 2) are directed towards software development and IT area. As shown in Figure 3 the most cited article is Dybå and Dingsøyr (2008), published in a prestigious publication rapidly increased its participation on total citation reaching the top of most cited articles rank in both indicators (see Table 2). Dybå and Dingsøyr (2008) present a very detailed review not only about agile methods but also on specific methods: XP, SCRUM, Crystal, DSDM, FDD, and Lean. The broader review made by the authors gave it latitude to be cited by several others studies, focusing on deeper view on one segment presented, as it is expressed in the keywords selected, such as empirical software engineering; evidence-based software engineering; systematic review; research synthesis; agile software development; XP; extreme programming; SCRUM. Dybå and Dingsøyr (2008) suggested that most of the studies reviewed were done on XP while Scrum was studied in only one surveyed article.

Figure 3 - Evolving changes in the top cited articles.

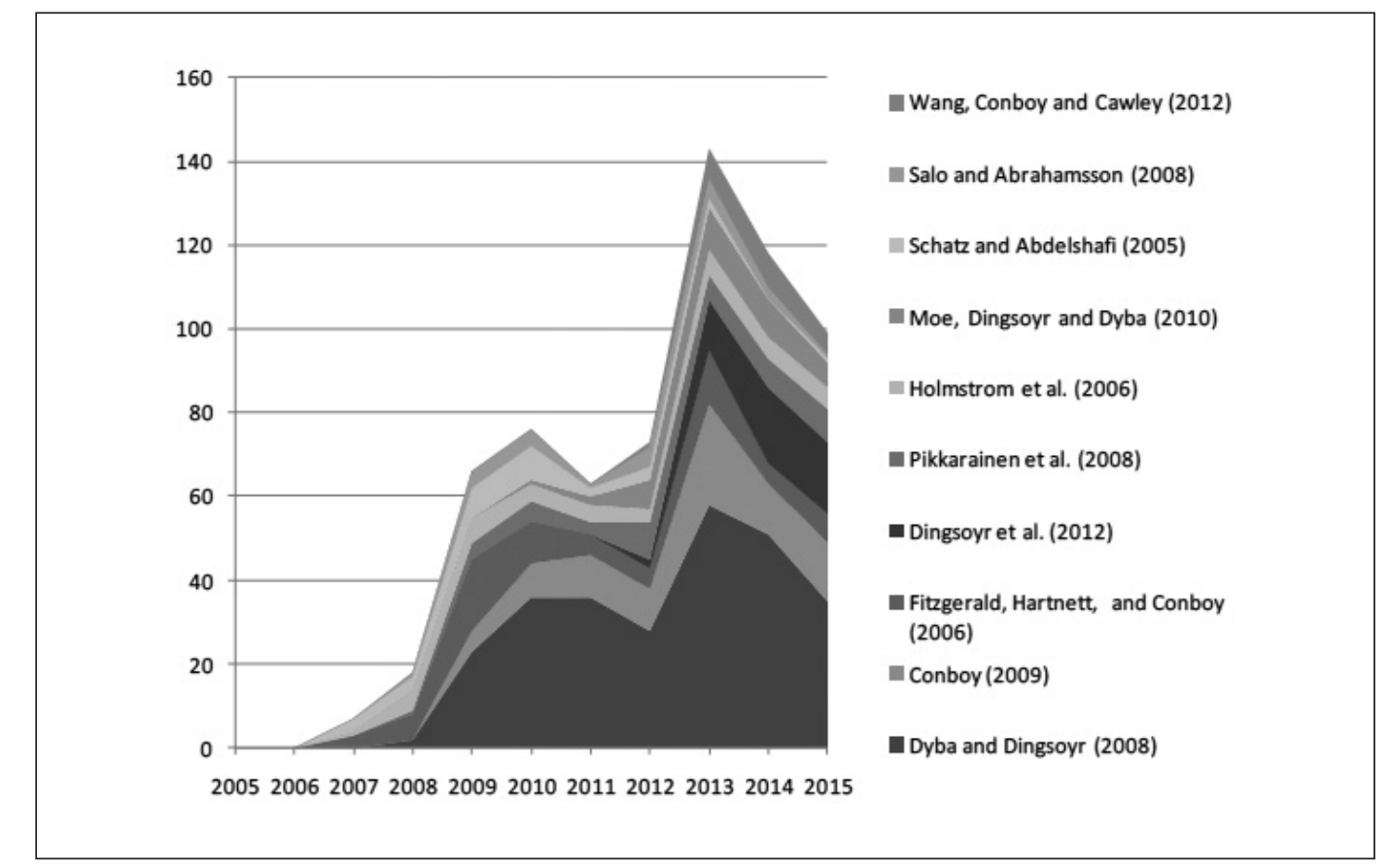

Source: Author (2015).

As expected as the number of authors studying a determined topic increases more articles became available and the participation of each on the total citation tends to reduce. What may be different about SCRUM is the dominance of Dybå and Dingsøyr (2008) as the most cited article for the last five straight years, as shown in Figure 3. 
Table 2 - Top articles: citations indicators.

\begin{tabular}{|l|r|r|}
\hline Article & Total citations & Citations/year \\
\hline Dyba and Dingsoyr (2008) & 269 & 30 \\
\hline Conboy (2009) & 83 & 10,38 \\
\hline Fitzgerald, Hartnett, and Conboy (2006) & 71 & 6,45 \\
\hline Dingsoyr et al. (2012) & 49 & 9,8 \\
\hline Pikkarainen et al. (2008) & 43 & 4,78 \\
\hline Holms trom et al. (2006) & 39 & 3,55 \\
\hline Moe, Dingsoyr and Dyba (2010) & 35 & 5 \\
\hline Schatz and Abdelshafi (2005) & 29 & 2,42 \\
\hline Salo and Abrahams son (2008) & 24 & 2,67 \\
\hline Wang, Conboy and Cawley (2012) & 21 & 4,2 \\
\hline
\end{tabular}

Source: Author (2015).

The second in the citation rank, Conboy (2009), focused more on information systems development (ISD) agility than methods as XP or Scrum, developing a definition and formative taxonomy of agility in an ISD context. The third one, Fitzgerald, Hartnett and Conboy (2006), presents the case of Intel Shannon in applying and customizing agile methods to software practices. However, the third place considering the average citation per year is Dingsoyr et al. (2012) (see Table 2) A decade of agile methodologies: Towards explaining agile software development presents the citations evolving changes of the top ten most cited articles. The articles Rising and Janoff (2000) and Highsmith and Cockburn (2001) had their citation volume reduced and also lost participation on the total citation, mainly from 2002 to 2009, when newer articles started to be cited.

The core articles (see Figure 3 and Table 2), considering the number of citation as a Proxy for impact in the academic community, are in-depth analyzed in terms of the knowledge contribution for the facing new generation of studies.

Relationship networks can is a useful tool for bibliometric analysis. The first network constructed is the article co-citation (see Figure 4). According to Garfield, (2001) co-citation analysis is based primarily on identifying pairs of highly-cited articles, co-citation is essentially a forward-looking perspective, prove to be accurate markers for the emergence of new topics.

Figure 4 below presents the co-citation network which is constructed with the references listed in the 91 articles. The full network formed is composed of 2,325 studies. 
Figure 4 - Co-citation network for top $10 \%$ of article by citation.

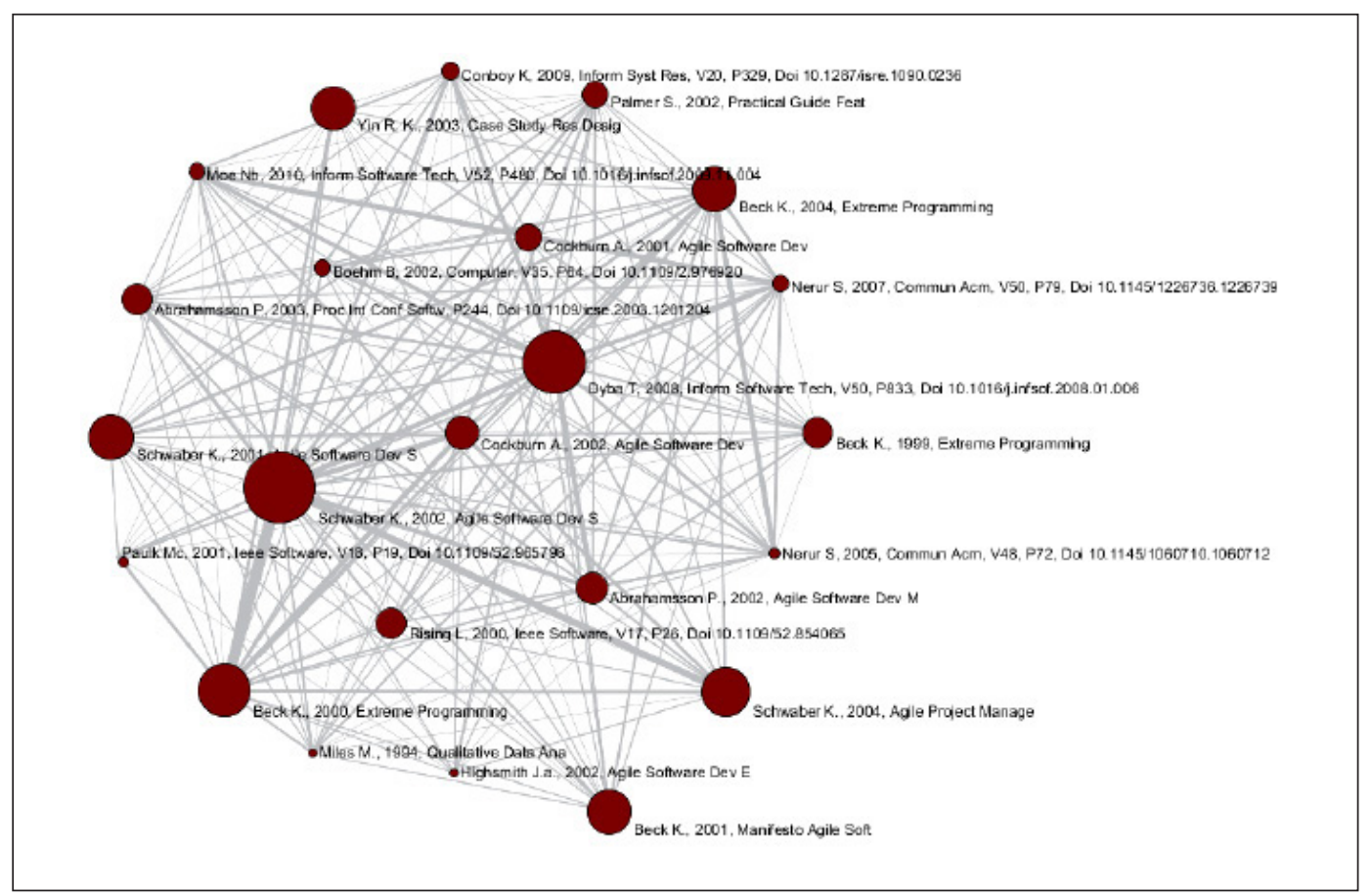

Note: 42 isolated nodes removal were removed. Software Sci2Tool.

Source: Author (2015).

The generated pool of cited article was trimmed for the $10 \%$ most cited works, associated with the 23 nodes generated, following the criteria used in Carvalho et al. (2013).

The size of the circles in Figure 4 representing the articles is proportional to the number of citations they received and the thickness of the arrow connecting to articles correlates with the number of times the authors of connected articles cited each other. The co-citation network reveals that even though Dybå and Dingsøyr (2008) was the most cited in the sample of 91, Schwaber and Beedle (2002) is the one more frequently cited in those articles related to "AGILE" and "SCRUM". Schwaber and Beedle (2002) refer to the book "Agile Software Development with SCRUM". Other articles by the same authors, about Agile Software Development and Management, are also highly cited.

Besides that, one can notice that 2 of the top cited articles (see Figure 3) are also present in the $10 \%$ most cited references of the whole 91 articles (DYBÅ; DINGSØYR, 2008; MOE et al., 2010). Those are articles are broader review coverage of the agile theme, what may explain the citation volume received. 
The co-authorship network presented in Figure 5 reveals that considering the top 20 most cited articles, there are co-authorship relationships between well-defined groups, and some groups do have the behavior of cross-citing its members. Figure 6 presents the article citation network for the 91 articles in the original sample, the local citation count. From the network, it is possible to visualize that cluster of the author does exist and that there is little connection among groups of works.

Figure 5 - Co-authorship network - Top 20 by citation.

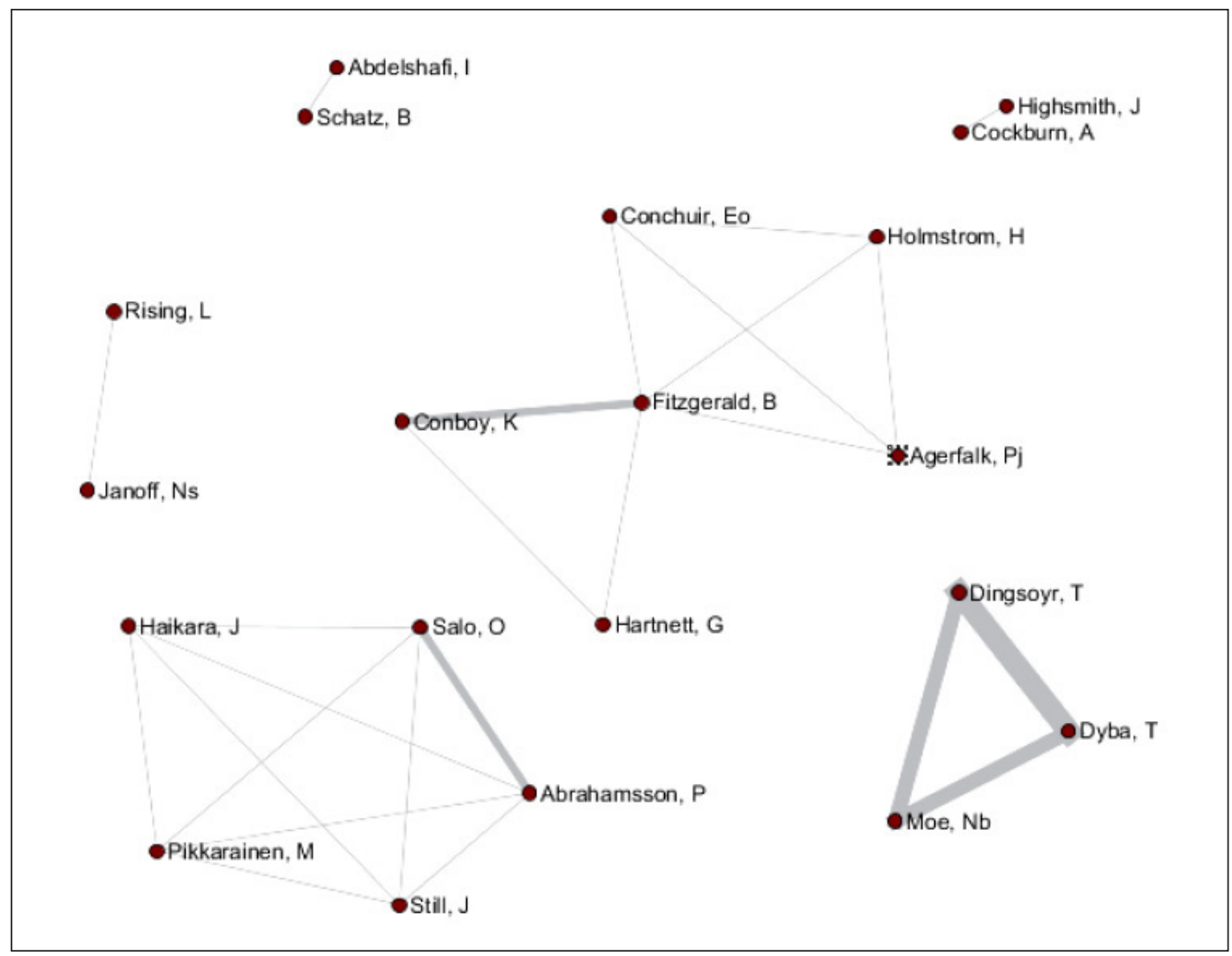

Note: Software Sci2Tool. Source: Author (2015).

Co-authorship analysis revealed that closed clusters of authors do exist and those clusters all reside in the software engineering research area, pointing out that SCRUM has been studied by the software community.

Considering the network centrality analysis output generated by Sci2Tool, presented in Table 3, Nerur and Balijepally. (2007) appears as the most central study followed by Miles and Huberman (1994) and Highsmith (2002). The best-ranked article from the original sample is Dybå and Dingsøyr (2008) in 6th place. Finally, on Table 3, reading the article's name, it is possible to notice that only one work is related SCRUM and are all related to SCRUM application in the software industry. 
Table 3 - Co-citation network indicators.

\begin{tabular}{|c|c|c|c|}
\hline Author & Title & $\begin{array}{c}\text { Local } \\
\text { citation }\end{array}$ & $\begin{array}{l}\text { On } \\
\text { original } \\
\text { set of } 91\end{array}$ \\
\hline Nerur and Balijepally. (2007) & Theoretical reflections on agile development methodologies & 8 & * \\
\hline Miles and Huberman (1994). & Qualitative data analysis: An expanded sourcebook & 6 & * \\
\hline Highsmith (2002) & Agile software development ecosystems. & 6 & * \\
\hline Paulk (2001) & Extreme programming from a CMM perspective & 6 & * \\
\hline Schwaber and Beedle (2002) & Agile Software Development with Scrum & 24 & * \\
\hline Dybå and Dingsøyr (2008) & $\begin{array}{l}\text { Empirical studies of agile software development: a } \\
\text { systematic review }\end{array}$ & 17 & Yes \\
\hline Beck (2000) & Extreme Programming Explained: Embrace Change & 19 & * \\
\hline Schwaber (2004) & Agile Project Management with Scrum & 16 & * \\
\hline Schwaber and Beedle (2001) & Agile Software Development with Scrum & 11 & * \\
\hline Beck et al. (2001) & Agile manifesto & 10 & * \\
\hline Beck ( 2004) & $\begin{array}{l}\text { Extreme Programming Explained: Embrace Change (2nd } \\
\text { edition) }\end{array}$ & 14 & * \\
\hline Yin (2003) & Case Study Research: Design and Methods & 7 & * \\
\hline Cockburn (2002) & Agile software development joins the 'would-be' crowd" & 10 & * \\
\hline Abrahamsson et al. (2002) & Agile software development methods: Review and Analysis. & 10 & * \\
\hline Abrahamsson (2003) & $\begin{array}{l}\text { Extreme programming: first results from a controlled case } \\
\text { study }\end{array}$ & 9 & * \\
\hline Rising and Janoff (2000) & The Scrum software development process for small teams & 8 & Yes \\
\hline Beck (1999) & Embrace change with extreme programming & 7 & * \\
\hline Cockburn and Highsmith (2001) & Agile software development: The people factor & 7 & * \\
\hline Palmer S., 2002 & A practical guide to feature-driven development & 8 & * \\
\hline Conboy (2009) & $\begin{array}{l}\text { Agility from first principles: reconstructing the concept of } \\
\text { agility in information systems development }\end{array}$ & 7 & * \\
\hline Boehm (2002) & Get ready for agile methods, with care & 7 & * \\
\hline Moe et al. (2010) & $\begin{array}{l}\text { A teamwork model for understanding an agile team: A case } \\
\text { study of a Scrum project }\end{array}$ & 7 & Yes \\
\hline Nerur et al. (2005) & Challenges of migrating to agile methodologies & 7 & * \\
\hline
\end{tabular}

Source: Author (2015). 
Figure 6 - Article citation network.

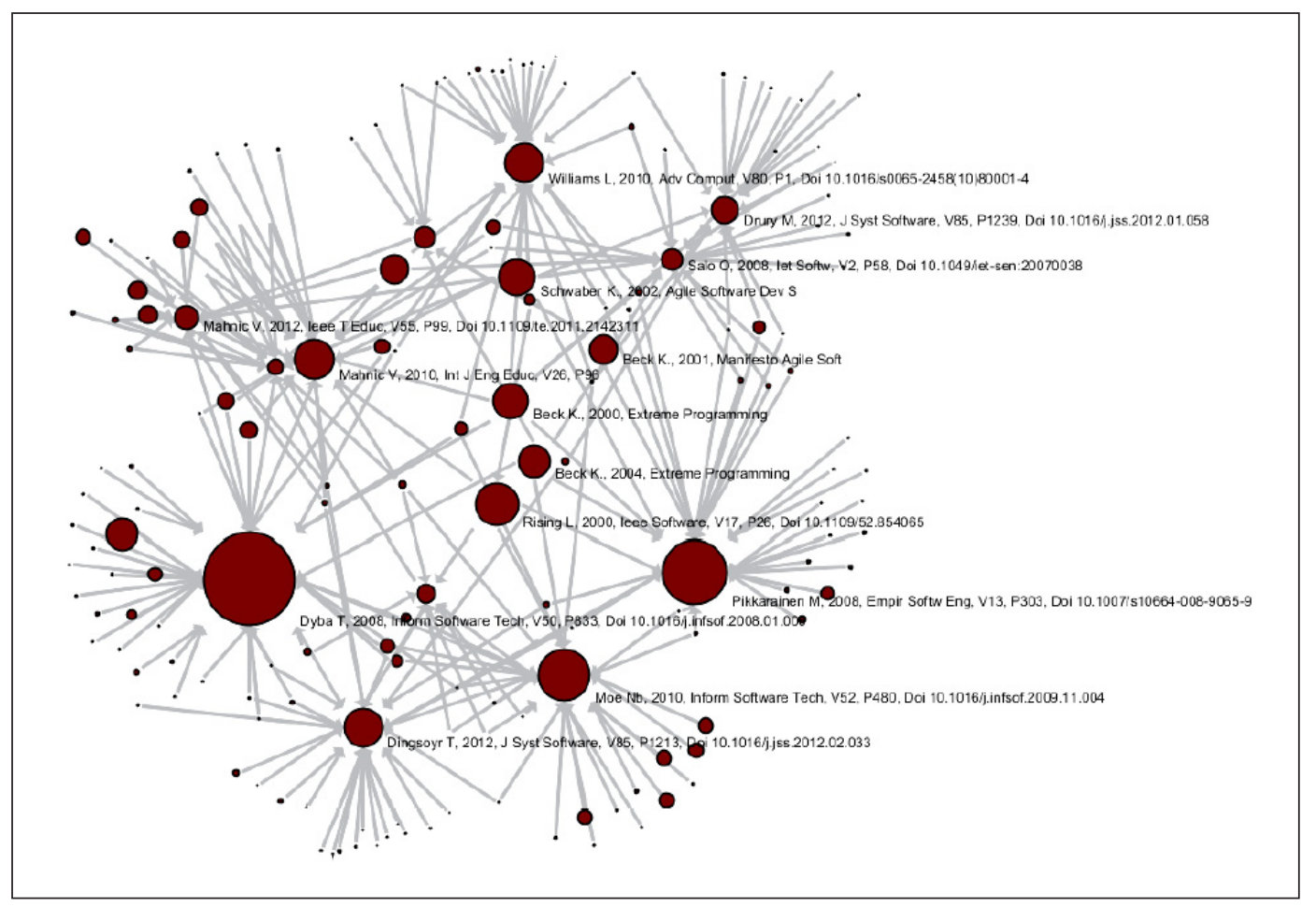

Note: Centrality for local citation count greater than zero without isolated nodes. Software Sci2Tool.

Source: Author (2015).

\section{DISCUSSION: CORE THEMES, TREND AND GAPS}

In this section the core themes, trends and gaps are explored.

Analyzing the number of publications (see Table 1) and citations (see Figure 2), the evolving pattern suggest that agile software development methods are in a productive debate in academic journals, despite hope that some author hope this is a passing fad. Laanti et al. (2011).

The keyword network was used for a quantitative assessment of the core themes, and the qualitative analysis was performed in the content analysis.

The two keywords used in the searching processes (SCRUM and Agile) stood out in the keyword network (see Figure 6). Considering the top 20 keywords by citation count, the most common keywords are related to agile (agile software development, agile methods, agile project management).

The keyword network (see Figure 7) also shows that SCRUM is usually compared with other agile methods as XP and Extreme Programing. According to Dybå and Dingsøyr (2008), there is not a unified view of current practice on agile and some findings are contradictory, what may explain the comparison of these methods. 
Figure 7 - Keyword network top 20 by occurrence.

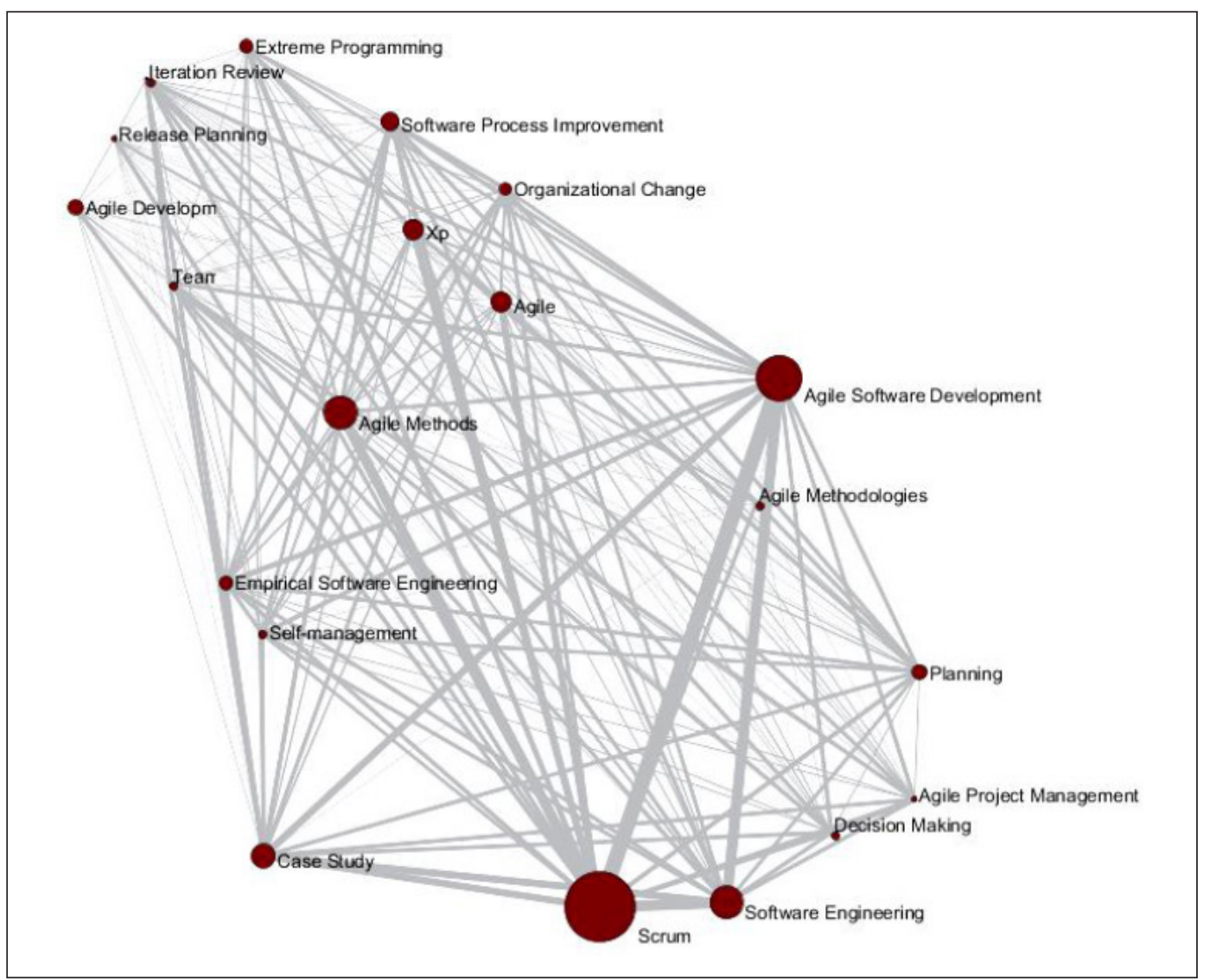

Source: Author (2015).

Research themes related to the soft side in agile methods are increasing as in project management field as a whole (CARVALHO; RABECHINI JR, 2015). Figure 7 also shows that the soft aspects related to organizational change, self-management and teamwork are very relevant. Dybå and Dingsøyr (2008) and Highsmith and Cockburn (2001) emphasize software development team's characteristics when agile methods are applied. For Dybå and Dingsøyr (2008), three topics related to the soft side receive more attention: the impact of organizational culture, how collaborative work takes place in agile development, and what characterizes agile development teams. Moreover, the keyword decision making suggest that agile methods view changes from a perspective that it mirrors today's turbulent business and technology environment helping development team in facing this uncertainty (HIGHSMITH; COCKBURN, 2001). 
Besides, keywords related to software developments such as Software Process Improvement, Iteration Review, and Release Planning, for example, are commonly mentioned (see Figure 7).

The keyword analysis also corroborates that interesting on SCRUM remains related to software topics, what corroborates the analysis of the articles' main research area (see section 4.1). Thus, assertions like "in the last ten years the use of agile methods has become widespread (DINGSØYR et al., 2012) or "agile project management methods are gaining increased attention in the general field of project management (STETTINA; HÖRZ, 2014) or "press releases, scientific publications, and anecdotal evidence demonstrate that organizations worldwide are adopting agile software development methods at increasing speed" (SALO; ABRAHAMSSON, 2008), they are all right, but in the software development industries, considering the SCRUM approach.

In the content analysis, the importance customer in agile methods was highlighted. For Mann and Maurer (2005) the customer should be trained in the SCRUM process For Dyba and Dingsøyr (2008) integrating customer-supplier relationships is one of the key concepts. Besides, Bass (2015) highlight the profile of the product owner that should "arbitrate between conflicting customer requirements, approve release schedules, disseminate architectural design decisions, provide technical governance and propagate information across teams".

Several benefits are pointed out by the surveyed studies. SCRUM led to more satisfied developers with the product, fostered customer involvement and communication and impact on overtime and customer satisfaction (MANN; MAURER, 2005).

Dybå and Dingsøyr (2008) compare agile and traditional methods, concerning project management, productivity, product quality, and team characteristics. However, these authors highlighted the controversial findings and the lack of scientific support for many of the benefits claimed by the agile community. Conboy (2009) corroborates and argue that in distributed development and large teams context, rendering agile method comparison and many other activities very difficult.

\section{CONCLUSIONS}

From the bibliometric analysis and content analysis presented the publications pattern of SCRUM literature can be delineated. We identified 156 academic articles and used this initial sample to identify publications trends concerning journals, countries, and research areas. Ninety-one articles were in depth analyzed applying a mix of bibliometrics and content analysis, which results in a contribution in three ways, evolving patterns, main trends and main gaps. 
This research suggested that SCRUM and agile methods are not just a fad on practitioners' environment, but also sparked interest in the academic community, demonstrated by the expressive figures of a number of publications and citations. However, data presented suggest that these studies are indeed in the niche of computer science field, $82 \%$ of the 56 articles identified. The co-authorship analysis corroborates revealing one only cluster related the software engineering research area. Finally, the keyword analysis also suggests that interesting on SCRUM remains related to on software topics.

The main trends identified are related to studies comparing SCRUM with other agile methods as XP, and comparing traditional versus agile methods. The variables used by comparing the benefits and challenges of different agile methods and/or approaches are related to team and project characteristics, productivity, product quality, customer and team members satisfaction, and timeframe. There is still room for new research since there is a lack of strong evidence to support these comparisons. Moreover, research themes related to the soft side in agile methods are increasing as in project management field as a whole.

This research also pointed out practical and managerial implications. Several benefits are pointed out in the literature surveyed as mentioned before. However, there is still a lack of robust evidence of upstanding results, and companies should take care of some astonishing advantages advertised about agile methods. The study also shows an increasing maturity in the research that can support companies and practitioners to apply agile methods. Actually, it is in a prescriptive phase and has structure guidelines as proposed in PMI Agile Certified Practitioner (PMI-ACP) (PMI, 2015). For practitioners, as agile methods are becoming more popular and demanded by clients, particularly in the software industry, as argued by several authors, there are increase opportunities for learning.

This study presents clear limitations related to research method adopted. The bibliometric analysis reflects the biases of the databases used (ARCHAMBAULT et al., 2006). Even though ISI Web of Science database is indexed and articles were published in credited journals with calculated and normalized impact factor, by Journal Citation Report, it would be fair to assume that there may have other relevant articles not considered in this study. We mitigate this limitation by searching in Scopus database. The search strings also represent limitations, since articles like Takeuchi and Nonaka (1986) that is in the surveyed databases did not appear in the search processes, despite being a seminal paper on this subject. Another limitation is on the use of citation counts as the main driver for the bibliometric analysis, which assumes that most frequent cited articles are more relevant for knowledge creation than other with lower citation counts. In order to overcome those limitations, futures studies could include a large number of databases as sources of articles or apply other methodologies such as the literature review and explore other search strings.

Finally, this study shows the opportunity for future studies to investigate the barriers to applying SCRUM in other industries than software. Some authors suggest that agile methods can be impacted by the contingent effect of project context, particularly in distributed development and large teams, what should be in depth investigated. Besides, there is an opportunity for verifying how those agile methods applied to software development interact with other projects managed by Project Management Offices. 


\section{REFERENCES}

ABRAHAMSSON, P. Extreme programming: first results from a controlled case study. In: EUROMICRO CONFERENCE, 29, Oulu, Finlândia. Anais... Proceedings IEEE, 2003.

ABRAHAMSSON P.; SALO O.; RONKAINEN J.; WARSTA J. Agile software development methods. VTT Publications, v. 478, 2002.

ARCHAMBAULT, E.; VIGNOLA-GAGNE, E.; COTE, G.; LARIVIERE, V.; GINGRAS,Y. Benchmarking scientific output in the social sciences and humanities: The limits of existing databases. Scientometrics, v. 68, n.3, p. 329-342, 2006.

BASS, JM. How product owner teams scale agile methods to large distributed enterprises. Empirical Software Engineering, v. 20, n. 6, p. 1525-1557, 2015

CARVALHO, M.M. FLEURY, A.L.; LOPES, A.P. An overview of the literature on technology roadmapping (TRM): Contributions and trends. Technological Forecasting \& Social Change, v.80, n.7, p. 1418-1437, 2013.

COOK, D. J.; MULROW, C. D.; HAYNES, R. B. Systematic reviews: synthesis of best evidence for clinical decisions. Annals of internal medicine, v.126, n.5, p. 376-380, 1997.

DINGSØYR, T.; HANSSEN, G. K.; DYBÅ, T.; ANKER, G.; NYGAARD, J. O. Developing software with scrum in a small cross-organizational project. Software Process Improvement, v. 4257, p. 5-15, 2006.

DINGSØYR, T.; NERUR, S.; BALIJEPALLY, V.; MOE, N. B. A decade of agile methodologies: Towards explaining agile software development. Journal of Systems and Software, v. 85, n.6, p. 1213-1221, 2012.

DURIAU, V.J. REGER, R.K.; PFARRER. M.D. A content analysis of the content analysis literature in organization studies research themes, data sources, and methodological refinements. Organizational Research Methods, v. 10, n.1, p. 5-34, 2007.

DYBÅ, T.; DINGSØYR, T. Empirical studies of agile software development: A systematic review. Information and Software Technology, v. 50, n.9, p. 833-859, 2008.

FITZGERALD, B.; HARTNETT, G.; \& CONBOY, K. Customising agile methods to software practices at Intel Shannon. European Journal of Information Systems, v. 15, n.2, p. 200-213, 2006.

FREEMAN, L. C. Centrality in social networks conceptual clarification. Social networks, v. 1, n.3, p. 215-239, 1978. 
GARFIELD, E. From bibliographic coupling to co-citation analysis via algorithmic historio-bibliography: A citationist's tribute to Belver C. Griffith, Lazerow Lecture presented at Drexel University, Philadelphia, PA., 2001.

HIGHSMITH, J. A. Agile software development ecosystems. Boston, MA: Addison-Wesley, 2002.

HIGHSMITH, J.; COCKBURN, A. Agile software development: The Business of Innovation Computer, v. 34, n. 9, p. 120-127, 2001.

HODA, R.; NOBLE, J.; MARSHALL, S. Self-organizing roles on agile software development teams. Software Engineering, IEEE Transactions on, v. 39, n. 3, p. 422-444, 2013.

HUMMEL, M. State-of-the-Art: A Systematic Literature Review on Agile Information Systems Development. In: SYSTEM SCIENCES, 47, Hawaii, 2014. Anais... (HICSS) IEEE, 2014.

LAANTI, M.; SALO, O.; ABRAHAMSSON, P. Agile methods rapidly replacing traditional methods at Nokia: A survey of opinions on agile transformation. Information and Software Technology, v. 53, n. 3, p. 276-290, 2011.

MANN, C.; MAURER, F. A case study on the impact of scrum on overtime and customer satisfaction. In: AGILE DEVELOPMENT CONFERENCE, 2005. Disponível em: <https://www. semanticscholar.org/paper/A-Case-Study-on-the-Impact-of-Scrum-on-Overtime-Mann-Maurer/af5619d8279c5939feafcc095bace26beb13d618/pdf>. Acesso em: set. 2015.

MAURER, F.; MARTEL, S. Extreme programming: Rapid development for web-based applications. IEEE Internet computing, v. 6, n. 1, p. 86, 2002.

MILES, M. B.; HUBERMAN, A. M. Qualitative data analysis: An expanded sourcebook. Sage, 1994 .

NERUR, S.; BALIJEPALLY, V. Theoretical reflections on agile development methodologies. Communications of the ACM, v. 50, n. 3, p. 79-83, 2007.

MOE, N. B.; DINGSØYR, T.; DYBÅ, T. A teamwork model for understanding an agile team: A case study of a Scrum project. Information and Software Technology, v. 52, n. 5, p. 480-491, 2010.

MOED, H. F. The impact-factors debate: the ISI's uses and limits. Nature, v. 415, n. 6873, p. 731-732, 2002.

NERUR, S.; MAHAPATRA, R. K.; MANGALARAJ, G. Challenges of migrating to agile methodologies. Communications of the ACM, v. 48, n. 5, p. 72-78, 2005.

OPSAHL, T.; AGNEESSENS, F.; SKVORETZ, J. Node centrality in weighted networks: Generalizing degree and shortest paths. Social Networks, v. 32, n. 3, p. 245-251, 2010. 
PIKKARAINEN, M.; HAIKARA, J.; SALO, O.; ABRAHAMSSON, P.; STILL, J. The impact of agile practices on communication in software development. Empirical Software Engineering, v. 13, n. 3, p. 303-337, 2008.

PMI - Agile Certified Practitioner (PMI-ACP) ${ }^{\triangleright}$ Handbook last updated on 7 December 2015.

(C) 2011-2015. Project Management Institute, Inc. All rights reserved. Revised: 2015

PRITCHARD, A. Statistical bibliography or bibliometrics. Journal of Documentation, v. 25, p. 348, 1969.

QIU, J. P.; DONG, K.; YU, H. Q. Comparative study on structure and correlation among author co-occurrence networks in bibliometrics. Scientometrics, v. 101, n.2, p. 1345-1360, 2014.

REUTERS, T. Using bibliometrics: a guide to evaluating research performance with citation data. Philadelphia, Thomson Reuters, 2008. Disponível em: $<$ http://ip-science.thomsonreuters.com/m/pdfs/325133_thomson.pdf. $>$. Acesso em set. 2015.

RISING, L.; JANOFF, N. S. The Scrum software development process for small teams. IEEE software, v. 17, n.4, p. 26-32, 2000.

SALO, O.; ABRAHAMSSON, P. Agile methods in European embedded software development organisations: a survey on the actual use and usefulness of Extreme Programming and Scrum. Software, IET, v. 2, n.1, p. 58-64, 2008.

SCHWABER, K.; BEEDLE, M. Agile Software Development with Scrum. Prentice Hall, Upper Saddle River, 2002.

STETTINA, C. J.; HÖRZ, J. Agile portfolio management: An empirical perspective on the practice in use. International Journal of Project Management, v. 33, n.1, p. 140-152, 2014.

TAKEUCHI, H.; NONAKA, I. The New New Product Development Game. Harvard Business Review, v. 86116, p. 137-146, 1986.

VLAANDEREN, K.; JANSEN, S.; BRINKKEMPER, S.; JASPERS, E. The agile requirements refinery: Applying SCRUM principles to software product management. Information and Software Technology, v. 53, n.1, p. 58-70. 2011.

VLIETLAND, J.; VAN VLIET, H. Towards a governance framework for chains of Scrum teams. Information and Software Technology, v. 57, p. 52-65, 2015.

ZIEGLER, B. E. Methods for bibliometric analysis of research: renewable energy case study. 2009. 171 f. Dissertação (Mestrado em Engenharia Elétrica e Ciências da Computação) - Massachusetts Institute of Technology, Massachusetts, Estados Unidos, 2009. 